INTRODUCTION

\title{
Primary and secondary infections of the spine
}

\author{
Doniel Drazin, MD, Jens R. Chapman, MD, ${ }^{2}$ Andrew Dailey, MD, ${ }^{3}$ and John Street, MD, $\mathrm{PhD}^{4}$ \\ ${ }^{1}$ College of Medicine, Pacific Northwest University of Health Sciences, Yakima; ${ }^{2}$ Swedish Neuroscience Institute, Seattle, \\ Washington; ${ }^{3}$ Department of Neurosurgery, University of Utah, Salt Lake City, Utah; and ${ }^{4}$ Department of Orthopaedics, University \\ of British Columbia, Vancouver, British Columbia, Canada
}

$\mathrm{T}$ HIS issue of Neurosurgical Focus presents articles related to different aspects of primary and postoperative infections of the spine. The articles explore current trends in the identification, epidemiology, treatment, and outcomes of spondylodiscitis and spinal epidural abscesses.

The issue leads off with an article that focuses on the importance of screening for endocarditis in patients with spinal infections. The next article highlights the increasing frequency of intravenous drug abuse-associated spinal epidural abscess and discusses the evidence that this may be an unexpected consequence of the catastrophic opioid epidemic.

The next set of scholarly articles report on the outcomes of surgery (decompression and/or fusion) for spinal infection from the cervical to the lumbar spine. One article explores the effect (complication rates, reoperation rates, and healthcare utilization) of using bone morphogenetic protein in patients with spinal infections.
The issue concludes with 2 systematic review articles. One review article looks at the effect of prophylactic vancomycin powder on gram-negative pathogens, and the other article reviews parasitic infections of the spine.

Primary pyogenic spinal infection represents a rapidly growing socioeconomic and healthcare challenge, especially with at-risk groups. We feel confident that the articles selected for this issue of Neurosurgical Focus will update and expand the knowledge of our readers and help them identify, evaluate, and manage spinal infections.

https://thejns.org/doi/abs/10.3171/2018.10.FOCUS18588

\section{Disclosures}

The authors report no conflict of interest.

\section{Correspondence}

Doniel Drazin: ddrazin@gmail.com. 